\title{
Behavior of Cardiac Variables in Animals Exposed to Cigarette Smoke
}

\author{
Sergio A lberto Rupp de Paiva, Leonardo A ntonio Mamede Zornoff, Marina Politi O koshi, \\ Katashi O koshi, Antonio Carlos Cicogna, Alvaro Oscar Campana \\ Botucatu, SP - Brazil
}

\begin{abstract}
Objective - To assess the behavior of cardiac variables in animals exposed to cigarette smoke.

Methods - Two groups of Wistar rats were studied as follows: control group (C), comprising 28 animals; and smoking group $(S)$, comprising 23 animals exposed to cigarette smoke for 30 days. Left ventricular cardiac function was assessed in vivo with transthoracic echocardiography, and myocardial performance was analyzed in vitro in preparations of isolated left ventricular papillary muscle. The cardiac muscle was assessed in isometric contractions with an extracellular calcium concentration of $2.5 \mathrm{mmol} / \mathrm{L}$.
\end{abstract}

Results - No statistical difference was observed in the values of the body variables of the rats and in the mechanical data obtained from the papillary muscle between the control and smoking groups. The values of left ventricular systolic diameter were significantly greater in the smoking animals than in the control animals $(C=3.39 \pm 0.4 \mathrm{~mm}$ and $S=3.71 \pm 0.51 \mathrm{~mm}, P=0.02)$. A significant reduction was observed in systolic shortening fraction $(C=56.7 \pm 4.2 \%$ and $S=53.5 \pm 5.3 \%, P=0.02)$ and in ejection fraction $(C=$ $0.92 \pm 0.02$ and $S=0.89 \pm 0.04, P=0.01$ ).

Conclusion - The rats exposed to cigarette smoke had a reduction in left ventricular systolic function, although their myocardial function was preserved.

Key words: smoking; left ventricular junction; cigarette; echocardiography

Faculdade de Medicina de Botucatu, UNESP

Mailing address: Sérgio Alberto Rupp de Paiva - Faculdade de Medicina de Botucatu UNESP - 18618-000 - Botucatu, SP, Brazil - E-mail: paiva@fmb.unesp.br English version by Stela Maris C. e Gandour

Received - 10/1/02

Accepted - 2/17/03
Among health hazards caused by smoking, cardiovascular changes stand out. Smoking influences the prevalence of infarction through several mechanisms, such as endothelial dysfunction, greater oxidation of LDL-cholesterol, a reduction in HDL-cholesterol, an increase in the levels of adhesion molecules and fibrinogen, an increase in platelet aggregation, and an increase in the prevalence of vascular spasm ${ }^{1,2}$. English et al ${ }^{3}$ were the first to report a close relation between smoking and mortality due to ischemic heart disease, and they were followed by other authors who stressed that association ${ }^{4,5}$.

The proposed mechanisms, by which the constituents of cigarette smoke (carbon monoxide, nicotine, tar, and the substances contained in vapor) may cause myocardial infarction, are as follows: thrombosis, formation of atherosclerotic plaque, platelet aggregation, vasoconstriction, hypo$\mathrm{xia}$, and arrhythmia induction ${ }^{6}$. Although the association between the smoking habit and coronary heart disease is universally accepted, little is known about the morphofunctional effects of smoking directly on the heart.

Thus, the objective of this study was to assess the behavior of the variables related to myocardial mechanical function and also to in situ heart function of the animals exposed to cigarette smoke.

\section{Methods}

The study comprised 51 male Wistar rats weighing between 200 and $250 \mathrm{~g}$ divided into 2 groups as follows: control group (C) - formed by 28 animals, receiving the diet routinely used in our laboratory adjusted according to the daily ingestion observed in group $\mathrm{S}$ during smoke exposure; and smoking group (S) - formed by 23 animals receiving the unrestricted diet routinely used in our laboratory for 3 months and exposed to tobacco smoke in the last 30 days.

The method used was that proposed by Simani et al ${ }^{7}$ and implemented by Wang et al ${ }^{8}$ to expose the animals to cigarette smoke in a modified incubator. The rats, 5 each time, were placed in the clear chamber connected to the smoking device. Smoke puffs were drawn from a cigarette 
by vacuum and then blown inside the chamber. Smoke was released at a rate of 5 cigarettes $/ 30$ minutes/day, twice in the afternoon, at 5-minute rest intervals in the first week. From the second week onwards, the number of cigarettes was increased to a rate of 10 cigarettes $/ 30$ minutes, twice in the morning and twice in the afternoon until the end of the study period. Fifteen animals were exposed to the smoke of 40 cigarettes/day each time. The total amount of smoke was derived from 940 cigarettes during the period of 4 weeks. According to the manufacturer, each cigarette used in the experiment provided $14 \mathrm{mg}$ of tar, $1.1 \mathrm{mg}$ of nicotine, and $15 \mathrm{mg}$ of carbon monoxide.

All animals underwent echocardiography, and, after an average of 3 days, they were euthanized for papillary muscle study. The animals were not exposed to cigarette smoke on the day of echocardiography or euthanasia.

At the end of the experimental period, the rats underwent anesthesia with ketamine hydrochloride $(50 \mathrm{mg} / \mathrm{kg})$ and xylidine hydrochloride $(1 \mathrm{mg} / \mathrm{kg})$ by the intramuscular route. Then, the anterior region of the thorax was epilated. After these procedures, the animals were placed in the left lateral decubitus position for undergoing echocardiography.

The echocardiograph used was the Sonos 2000 model (Hewlett-Packard Co.) equipped with a 7.5-MHz electronic transducer. Flow assessment was performed with the same transducer operating at 5.0 MHz. To measure the cardiac structures, M-mode images with the ultrasound beam oriented by the 2-dimensional image with the transducer in the parasternal short-axis view were used. The image of the left ventricular cavity was obtained placing the M-mode cursor right below the plane of the mitral valve between the papillary muscles. The images of the aorta and of the left atrium were also obtained in the parasternal short-axis view with the M-mode cursor positioned at the level of the aortic valve. Recording of one-dimensional imaging (velocity $=$ $100 \mathrm{~mm} / \mathrm{s}$ ) was performed with the UP-890MD model printer (Sony Co.). Later, the cardiac structures were manually measured with the aid of a precision pachymeter according to the recommendations of the American Society of Echocardiography ${ }^{9}$. The cardiac structures were measured in at least 5 consecutive cardiac cycles. Left ventricular diastolic diameter (LVDD) and left ventricular posterior wall thickness (LVPWT) were measured at the moment corresponding to its maximal diameter. Left ventricular systolic diameter (LVSD) was measured at the moment of the maximal systolic excursion of the posterior wall. Left ventricular systolic function was assessed calculating the systolic shortening fraction [(LVDD-LVSD)/LVDD x 100] and the ejection fraction $\left[\left(\mathrm{LVDD}^{3}-\mathrm{LVSD}^{3}\right) / \mathrm{LVDD}^{3}\right]$. Transmitral diastolic flow (E and A waves) was obtained with the transducer in the 4chamber apical view. The flows were directly measured in the echocardiographic monitor.

The study of the isolated papillary flow was performed according to already described procedures 3 days after echocardiography ${ }^{10-12}$. The mechanical function was studied in left ventricular papillary muscles obtained as follows: the rat was beheaded, its thorax opened, the heart rapidly removed and placed in Krebs-Henseleit solution previously oxygenated (10 minutes) with $95 \%$ oxygen $\left(\mathrm{O}_{2}\right)$ and $5 \%$ carbon dioxide $\left(\mathrm{CO}_{2}\right)$ at a temperature of $28^{\circ} \mathrm{C}$. After dissection of the left ventricle and sectioning of the interventricular septum, the left ventricle was divided into 2 parts, each containing its papillary muscle, and, then, carefully dissected in a glass chamber, constantly oxygenated and maintained at $28^{\circ} \mathrm{C}$. The papillary muscles, after having their extremities tied to 2 stainless steel rings, were rapidly transferred to the glass chamber containing the Krebs-Henseleit solution, which was constantly oxygenated with $95 \% \mathrm{O}_{2}$ and $5 \% \mathrm{CO}_{2}$ and maintained at $28^{\circ} \mathrm{C}$ due to the use of a circulating bath. The papillary muscles were maintained in the vertical position in the glass chamber. The inferior ring was attached to a stainless steel wire of $0.031-\mathrm{cm}$-diameter connected to an outer transducer (Kyowa 120T-20B), and the superior ring was connected to a stainless steel wire similar to the former tied to the extremity of the long arm of an isotonic lever. A micrometer was placed on that extremity to control the extension of the movements of the lever, providing muscle length adjustment in the muscular relaxation phase. Initial stretching of the cardiac fiber was performed with a light load (preload) suspended in the extremity of the short arm of the lever coupled to the 7 DCDT - 050 model length transducer (Hewlett Packard), which measured length variations during muscle contractions. The lever was rigid and light, made of aluminum with a 4:1 long arm/short arm ratio.

The muscles were stimulated 12 times per minute with platinum needle electrodes, which were coupled to an electric stimulator programmed to release stimuli in 5-ms square waves, with a voltage approximately $10 \%$ greater than the minimum necessary to cause a maximal mechanical response of the muscle.

The composition of the Krebs-Henseleit solution ${ }^{13}$ in millimoles per liter was as follows: $118.5 \mathrm{NaCl} ; 4.69 \mathrm{KCl} ; 2.52$ $\mathrm{CaCl}_{2} ; 1.16 \mathrm{MgSO}_{4} ; 1.18 \mathrm{KH}_{2} \mathrm{PO}_{4} ; 5.50$ glucose; and 25.88 $\mathrm{NaHCO}_{3}$. The partial pressure of oxygen in the solution was maintained between 550 and $600 \mathrm{mmHg}$.

The parameters used to characterize the papillary muscles were length $(\mathrm{mm})$ and sectional area $\left(\mathrm{mm}^{2}\right)$. The in vitro length $\left(\mathrm{L}_{\max }\right)$ was obtained with a Gartner cathetometer. The sectional area was calculated based on the measures of the diameter of the central segment, considering that the muscle had a cylindrical geometrical form and specific weight of 1.0. The wet weights of the left and right ventricles (LV and RV, respectively) and atria (A), normalized to the final body weight of the rat (BW), were used as indices of atrial and ventricular hypertrophy.

The water content of the tissues was assessed by the ratio between the wet and dry weights of the following tissues: liver, lungs, left ventricle, and the calf muscle.

The variables studied were tested in regard to normality, and the mean values and the standard deviations of the groups studied were calculated. In the case of normal distribution, the Student $t$ test was used for comparison between the control and smoking groups. For the nonparametric variables, the values of the median and the interquartile intervals of the groups studied were calculated. The MannWhitney test was used to compare the groups ${ }^{14}$. The Sig- 
maStat for Windows v 2.0 statistical package (Jandel Co., San Rafael, CA, USA) was used for the tests. The significance level of $5 \%$ was adopted for all tests.

\section{Results}

The body variables of the animals are shown in table I and the mechanical data of the isolated papillary muscles are shown in table II. No statistical difference was observed in the values of the body variables and the data obtained from the papillary muscle when comparing the control and smoking groups.

Table III shows the values obtained in the echocardiographic study. The values of left ventricular systolic diameter were significantly greater in the smoking animals than in the controls. Exposure to cigarette smoke caused a significant reduction in left ventricular systolic function indices (systolic shortening fraction and ejection fraction). No difference was observed between the groups of rats when comparing the other echocardiographic variables studied.

\section{Discussion}

This study aimed at assessing the behavior of the cardiac variables of rats exposed to cigarette smoke. The

\begin{tabular}{|lccr|}
\hline \multicolumn{4}{|c|}{ Table I - Body variables of the rats studied } \\
\hline & Control $(\mathrm{n}=28)$ & Smoker $(\mathrm{n}=23)$ & Test $(\mathrm{P})$ \\
\hline Initial weight $(\mathrm{g})$ & $252(250-260)$ & $254(249-262)$ & $\mathrm{MW}(0.90)$ \\
$\mathrm{BW}(\mathrm{g})$ & $407 \pm 42$ & $398 \pm 31$ & $t(0.38)$ \\
LV (g) & $0.755 \pm 0.1$ & $0.767 \pm 0.095$ & $t(0.66)$ \\
RV (g) & $0.214 \pm 0.043$ & $0.215 \pm 0.04$ & $t(0.91)$ \\
Atrium (g) & $0.091 \pm 0.018$ & $0.089 \pm 0.018$ & $t(0.73)$ \\
LV/BW & $1.85 \pm 0.18$ & $1.93 \pm 0.17$ & $t(0.16)$ \\
RV/BW & $0.52 \pm 0.09$ & $0.54 \pm 0.08$ & $t(0.53)$ \\
A/BW & $0.22 \pm 0.04$ & $0.22 \pm 0.05$ & $t(0.95)$ \\
Liver (W/D) & $3.22 \pm 0.1$ & $3.24 \pm 0.09$ & $t(0.63)$ \\
Lung (W/D) & $4.85 \pm 0.56$ & $4.92 \pm 0.41$ & $t(0.62)$ \\
LV (W/D) & $4.19(4.12-4.28)$ & $4.22(4.19-4.31)$ & MW $(0.12)$ \\
CSM (W/D) & $4.01(3.91-4.08)$ & $4.02(4-4.12)$ & MW $(0.44)$ \\
\hline
\end{tabular}

MW- Mann-Whitney test; LV- left ventricle; RV- right ventricle; A- atrium; BW- final body weight; W- wet weight; D- dry weight; CSM- calf skeletal muscle.

\begin{tabular}{|lccc|}
\hline \multicolumn{4}{|c|}{ Table II - Variables obtained through the study of papillary muscle } \\
\hline & Control $(\mathrm{n}=28)$ & Smoker $(\mathrm{n}=23)$ & Test $(\mathrm{P})$ \\
\hline & $7.22 \pm 1.41$ & $7.75 \pm 1.7$ & $t(0.23)$ \\
$\mathrm{TD}(\mathrm{g} / \mathrm{mm} 2)$ & $1.08 \pm 0.32$ & $1.04 \pm 0.41$ & $t(0.71)$ \\
$\mathrm{TR}(\mathrm{g} / \mathrm{mm} 2)$ & $166 \pm 14$ & $160 \pm 15$ & $t(0.11)$ \\
$\mathrm{TPT}(\mathrm{ms})$ & $221 \pm 29$ & $217 \pm 20$ & $t(0.62)$ \\
$\mathrm{TR}$ & $74.5 \pm 16.5$ & $82.0 \pm 19.8$ & $t(0.15)$ \\
$+\mathrm{dT} / \mathrm{dt}\left(\mathrm{g} / \mathrm{mm}^{2} / \mathrm{s}\right)$ & $21.9 \pm 4.3$ & $23.4 \pm 5.5$ & $t(0.26)$ \\
$-\mathrm{dT} / \mathrm{dt}\left(\mathrm{g} / \mathrm{mm}^{2} / \mathrm{s}\right)$ & $1.04 \pm 0.21$ & $1.02 \pm 0.25$ & $t(0.84)$ \\
$\mathrm{SA}\left(\mathrm{mm}{ }^{2}\right)$ & &
\end{tabular}

\begin{tabular}{|lccc|}
\hline \multicolumn{4}{|c|}{$\begin{array}{c}\text { Table III - Variables related to the dimensions of the cardiac } \\
\text { structures and left ventricular function obtained on echocardiography }\end{array}$} \\
\hline & Control $(\mathrm{n}=28)$ & Smoker $(\mathrm{n}=23)$ & Test $(\mathrm{P})$ \\
\hline & $283 \pm 36$ & $286 \pm 33$ & teste $t(0.72)$ \\
\hline HR (bat/min) & $7.83 \pm 0.46$ & $7.94 \pm 0.34$ & teste $t(0.33)$ \\
LVDD $(\mathrm{mm})$ & $3.39 \pm 0.4$ & $3.71 \pm 0.51$ & teste $t(0.02)$ \\
LVSD $(\mathrm{mm})$ & $1.49 \pm 0.11$ & $1.49 \pm 0.12$ & teste $t(0.90)$ \\
LVDT(mm) & $0.19 \pm 0.011$ & $0.188 \pm 0.018$ & teste $t(0.62)$ \\
LVDT/LVDD & $3.96 \pm 0.3$ & $3.94 \pm 0.29$ & teste $t(0.83)$ \\
Aorta (mm) & $5.39 \pm 0.5$ & $5.56 \pm 0.49$ & teste $t(0.23)$ \\
LA (mm) & $56.7 \pm 4.2$ & $53.5 \pm 5.3$ & teste $t(0.02)$ \\
S $(\%)$ & $0.92 \pm 0.02$ & $0.89 \pm 0.04$ & teste $t(0.01)$ \\
EF & $1.55 \pm 0.29$ & $1.65 \pm 0.29$ & teste $t(0.27)$ \\
E/A & & &
\end{tabular}

animals underwent cigarette smoke inhalation, with all the components involved, for 30 days, and the functional changes were detected in vivo only through echocardiography.

Some deleterious effects of smoking on the cardiovascular system are widely accepted. It has already been well documented that smoking is the major changeable risk factor for acute myocardial infarction ${ }^{6,15}$. Although the effects of smoking on the coronary system have been intensely researched, the direct effects of smoke exposure on the heart are less known.

This study showed that chronic exposure to cigarette smoke resulted in effects on the rat's heart, whose detection depended on the method used for functional analysis. Considering the variables studied in the preparations with isolated papillary muscle, no difference could be identified between the 2 groups studied. This method allows the study of myocardial function without the interference of external factors, such as preload, afterload, and heart rate. As such, our results show that no change in the myocardial mechanical performance occurred due to cigarette smoke inhalation. On the other hand, an increase in left ventricular end systolic diameter was observed in the smoking group on echocardiography. In addition, both shortening and ejection fractions were statistically smaller in the smoking group. Thus, the results show that, despite the preservation of muscle function, the rats inhaling cigarette smoke had depressed left ventricular systolic function.

Some factors may explain our findings. In an experimental study with dogs, the acute administration of nicotine was accompanied by an increase in inotropism ${ }^{16}$. A significant difference in regard to our study, however, is that we did not use nicotine, but cigarette smoke. It is worth noting that more than 4,700 different substances have already been identified in cigarette smoke ${ }^{6}$, and some of these substances could counteract the inotropic effects of nicotine. Another aspect to be considered is that our animals were chronically exposed to cigarette smoke and that the acute cardiovascular effects of smoking may be different from the chronic ones ${ }^{17}$. 
One of the most significant cardiovascular effects of smoking is vasoconstriction. Of the pathophysiological mechanisms accepted to explain that phenomenon, the release of catecholamines by the central nervous terminations and of endothelin-1 stands out ${ }^{18,19}$. Thus, although contractility remains unaltered, the depression in left ventricular function could result from changes in the vascular tonus, with a consequent increase in the afterload.

Furthermore, considering the hemodynamic changes caused by adrenergic stimulation and release of endothelin-1 after nicotine infusion, these substances could cause sodium and water retention, and change the load conditions to which the heart is submitted ${ }^{20,21}$. Our study, however, identified neither changes in the body weights of the animals of the different groups, nor changes in the relations between the wet and dry weights of the different organs. Therefore, sodium and water retention may not have played a role in the results.
Another potential mechanism that could interfere with systolic performance in the animals studied could be changes in heart rate. The concept that nicotine infusion or cigarette smoke exposure could result in an increase in heart rate has been well accepted ${ }^{17,22}$. Our study, however, showed no difference in heart rate between the 2 groups.

In conclusion, this study showed that rats chronically exposed to cigarette smoke for 30 days had a depression in left ventricular function. Although speculative, our results suggest that these findings could be consequent to changes in load conditions to which the heart is submitted.

\section{Acknowledgements}

We thank Mr. Mario B. Bruno, Vitor Marcos de Souza, and José Carlos Georgete for their support.

\section{References}

1. Ridker PM, Genest J, Libby P. Risk factors for atherosclerotic disease. In: Heart Disease: a textbook of cardiovascular medicine (6th ed.), edited by Braunwald E, Zipes DP and Libby P. Philadelphia: W.B. Saunders Company, 2001, p. 1010-39.

2 Armaganijan D, Batlouni M. Impacto dos fatores de risco tradicionais. Rev Soc Cardiol Estado de São Paulo 2000; 10: 686-93.

3. English JP, Willius FA, Berkson J. Tobacco and coronary disease. JAMA 1940; 115: $1327-9$.

4. Willett WC, Green A, Stampfer MJ, et al. Relative and absolute excess risks of coronary heart disease among women who smoke cigarettes. N Engl J Med 1987; 317: 1303-9.

5. Doll R, Peto R. Mortality in relation to smoking: 20 years' observations on male British doctors. Br Med J 1976; 2: 1525-36.

6. Smith CJ, Fischer TH. Particulate and vapor phase constituents of cigarette mainstream smoke and risk of myocardial infarction. Atherosclerosis 2001; 158:257-67.

7. Simani AS, Inoue S, Hogg JC. Penetration of the respiratory epithelium of guinea pigs following exposure to cigarette smoke. Lab Invest 1974; 31: 75-81.

8. Wang XD, Liu C, Bronson RT, Smith DE, Krinsky NI, Russell M. Retinoid signaling and activator protein-1 expression in ferrets given beta-carotene supplements and exposed to tobacco smoke. J Natl Cancer Inst 1999; 91: 60-6.

9. Sahn DJ, DeMaria A, Kisslo J, Weyman AE. The Committee on M-Mode Standardization of the American Society of Echocardiography. Recommendations regarding quantitation in M-mode echocardiography: results of a survey of echocardiographic measurements. Circulation 1978; 58: 1072-83.

10. Cicogna AC, Padovani CR, Okoshi K, Aragon FF, Okoshi MP. Myocardial function during chronic food restriction in isolated hypertrophied cardiac muscle. Am J Med Sci 2000; 320: 244-8.

11. Cicogna AC, Padovani CR, Okoshi K, Matsubara LS, Aragon FF, Okoshi MP.
The influence of temporal food restriction on the performance os isolated cardiac muscle. Nutr Res 2001; 21: 639-48.

12. Cicogna AC, Padovani CR, Nardi SC, Okoshi MP. Efeito do envelhecimento sobre o comportamento mecânico dos músculos papilares de ratos wistar. Arq Bras Cardiol 1993; 60: 215-9.

13. Krebs HA, Henseleit K. Untersuchungen über die Harnstoff-bildung im Turkörper. Hoppe Deylers Z Physiol Chem 1932; 210: 33-66.

14. Glantz SA. Primer of Biostatistics. New York: McGraw-Hill, 1997. p473.

15. Hays JT, Dale LC, Hurt RD, Croghan IT. Trends in smoking-related diseases: why smoking cessation is still the best medicine. Postgrad Med 1998; 104: 56$62,5-6,71$.

16. Greenspan K, Edmands RE, Knoebel SB, Fisch C. Some effects of nicotine on cardiac automaticity, conduction, and inotropy. Arch Intern Med 1969; 123: 707-12.

17. Gidding SS, Xie X, Liu K, Manolio T, Flack JM, Gardin JM. Cardiac function in smokers and nonsmokers: the CARDIA study. The Coronary Artery Risk Development in Young Adults Study. J Am Coll Cardiol 1995; 26: 211-6.

18. Marano G, Ramirez A, Mori I, Ferrari AU. Sympathectomy inhibits the vasoactive effects of nicotine in conscious rats. Cardiovasc Res 1999; 42: 201-5.

19. Haak T, Jungmann E, Raab C, Usadel KH. Elevated endothelin-1 levels after cigarette smoking. Metabolism 1994; 43: 267-9.

20. Packer M. The neurohormonal hypothesis: a theory to explain the mechanism of disease progression in heart failure. J Am Coll Cardiol 1992; 20: 248-54.

21. Miyauchi T, MasakiT. Pathophysiology of endothelin in the cardiovascular system. Annu Rev Physiol 1999; 61: 391-415.

22. Tanus-Santos JE, Sampaio RC, Hyslop S, Franchini KG, Moreno H, Jr. Endothelin ET(A) receptor antagonism attenuates the pressor effects of nicotine in rats. Eur J Pharmacol 2000; 396: 33-7. 